\title{
Reflection on Consecutive Interpreting Note-taking Textbooks Published in China
}

\author{
Jing Luo, Xiao Ma \\ Translation and Interpreting Department, Wuhan University, Wuhan, PR China \\ Email address: \\ 412172187@qq.com (Jing Luo) \\ To cite this article: \\ Jing Luo, Xiao Ma. Reflection on Consecutive Interpreting Note-taking Textbooks Published in China. International Journal of Applied \\ Linguistics and Translation. Vol. 5, No. 1, 2019, pp. 9-14. doi: 10.11648/j.ijalt.20190501.12
}

Received: April 28, 2019; Accepted: May 30, 2019; Published: June 11, 2019

\begin{abstract}
Increasing international exchanges have made consecutive interpreting more and more prevalent nowadays, and the success of consecutive interpreting activities is, to a large extent, dependent on the interpreters' memory of the speaker's source information, and in order to do that, interpreters need to take notes in a methodical manner, which helps interpreters to enhance their concentration, activate memory, ensure accuracy, and reduce memory burden, thus improving the overall quality of consecutive interpreting. However, note-taking skills do not receive a fair amount of attention in interpreting textbooks, previous studies on and textbooks of consecutive interpreting usually overemphasize the individuality of the note-taking method and symbols system while neglecting the regularity and universality underpinning the note-taking system. This paper addresses this neglected aspect of consecutive interpreting note-taking textbook research and chooses four major note-taking textbooks published in China, comparing and analyzing their merits and demerits in terms of their positioning, theoretical elaboration of note-taking skills and the choice of note-taking practice materials etc. Four suggestions are presented as the findings of this study: 1). Clarify textbook positioning. 2). Combine note-taking techniques with selected exercise topics. 3). Diversify training materials and training methods. 4) Offer audio or video practice material so as to form a three-dimensional note-taking textbook system, which may hopefully provide some food for thought for the further compilation, development and research of note-taking textbooks.
\end{abstract}

Keywords: Note-taking Skill, Textbook Positioning, Note-Taking Theory, Note-Taking Practice

\section{Introduction}

Consecutive interpreting is an important type of interpreting, widely used in such occasions as press conferences, business negotiations, international conferences, high-level dialogues, academic seminars, high-level forums and so on. To facilitate the process of consecutive interpreting, interpreters usually rely on a special system of note-taking. According to Daniel Gile's Effort Model (1995, p. 179) [1], consecutive interpreting consists of two phases: The first phase of consecutive interpreting $=\mathrm{L}$ (listening and analysis) $+\mathrm{N}$ (note-taking) $+\mathrm{M}$ (short-term memory) $+\mathrm{C}$ (coordination). The second phase of consecutive interpreting $=\mathrm{R}$ (remembering) $+\mathrm{N}$ (note-reading) $+\mathrm{P}$ (production). It is obvious that notes (including note-taking and note-reading) are an indispensable part of consecutive interpreting. A successful note-taking technique for consecutive interpretation calls for a method of reducing words to ideas and putting the ideas to symbols that can then be re-expressed in another language (Nolan, 2005, p. 294) [2]. Jones (2008, p. 40) [3] pointed out that notes should reflect the form of a speech, making it clear to the interpreter what is important and what is ancillary, how ideas are related or separated from one another. The importance of note-taking can be found in many previous literature. For example, Seleskovitch (1968, p. 39) [4] once stated "note-taking acts as a mnemonic device, a memory aid which triggers the memory of what was understood when heard". Its purpose is to enable the interpreter to recover longer stretches of source speech from memory and to present the target version in fluent and natural delivery (Mikasa, 2017:72) [5]. It is an essential part of consecutive interpreting to compensate for the limited short-term memory capacity of the interpreter (Someya, 2017, p. 147) [6]. Jotting down cues on the paper as speech is understood in a way that visually represents the understanding provides comfort and mental security to the interpreter. This also helps to concentrate on comprehension and TL speech preparation (Ito, 2017, p. 62) [7]. Therefore, note-taking is 
considered one of the key skills that any interpreter has to master in conducting his/her job properly (Someya, 2017, p. 147) [6], so it should be made a crucial part of interpreting training and a crucial skill that the interpreting trainees must master.

\section{The Status Quo of the Consecutive Interpreting Note-Taking Textbooks Published in China}

At present, there are a variety of interpreting textbooks on the market focusing on interpreting types such as consecutive interpreting, simultaneous interpreting and sight interpreting etc., but the textbooks dedicated to note-taking skills are few and far between. According to the search results of on-line book selling website, there are only a handful of consecutive interpreting note-taking textbooks published in Mainland China. This paper selects four note-taking textbooks as shown in Table 1 to study: Zhongming Wu (2008) [8], Qiaolian Zhu (2009) [9] Tao Wang (2012) [10] and Andrew Gillies (2009) [11].

Table 1. Note-Taking Textbooks Published in China.

\begin{tabular}{lll}
\hline Textbook Name & Editor-in-Chief & Publishing House \\
\hline Practical Guidance for Note-Taking in Interpreting & Zhongming Wu & Wuhan University Press \\
English-Chinese Interpretation Note-taking Course & Tao Wang & Wuhan University Press \\
Effective Note-taking & Qiaolian Zhu & People's Education Press \\
Note-taking for Consecutive Interpreting: A Short Course & Andrew Gillies & Shanghai Foreign Language Education Press \\
\hline
\end{tabular}

These textbooks have played a certain role in the teaching and training of interpreting major. However, in terms of quantity alone, compared with other interpreting textbook, the development of the note-taking textbook is obviously lagging behind, and the research in this regard is still blank, which does not match the importance of the note-taking skills in consecutive interpreting. The author believes that it is necessary to evaluate and explore the advantages and disadvantages of existing note-taking textbooks by combining the characteristics of the note-taking course and her own interpreting practice and teaching experience, so as to accumulate experience for the preparation and development of future note-taking textbooks, thus helping to provide some enlightenment and food for thought for interpreting practice, teaching and research.

\subsection{Existing Interpreting Materials Do Not Give Enough Attention to Note-Taking}

In general, consecutive interpreting skills include the following aspects: short-term memory, note-taking, figure interpreting, attention coordination, comprehension, expression, sight interpreting, emergency coping tactics, interpretation preparation, public speech skills, cross-cultural communication awareness, professional ethics, etc. (Wang, 2006) [12]. However, most of the consecutive interpreting textbooks barely touch upon note-taking skills, and only a very limited number of studies have examined the features and classifications of the symbols used for note-taking in different combinations of languages and by different interpreters (Yang, 2017, p. 118) [13]. In most cases, they only list a few frequently used symbols, and give a few examples of note-taking demonstrations, systematic explanations and analysis are not presented, so the learners always have difficulty grasping the basic essentials, and they always assume that note-taking in consecutive interpreting "are covered with a mysterious veil" (Wen, 2008) [14], and note-taking skills becomes something only a handful of professional interpreters know about, which undermines the cultivation of interpreters.

\subsection{Over-Emphasizing the "Personality" of Consecutive Interpreting Notes Is Not Conducive to Interpreting Teaching}

Due to the limited compilation and research of interpreting note-taking textbook, there are some misunderstandings about the consecutive interpreting notes. It has been said that note-taking cannot be taught, and that everyone must come up with their own system. This is quite wrong (Gillies, 2009, p. 10) [11]. As Rozan (2003, p. 11) [15] pointed out, "If the fundamentals are in place then note-taking can easily be learnt." Indeed, notes in consecutive interpreting can be personal and individualized, but over-emphasizing the individuality and personality of note-taking while neglecting the regularity and systemicity will inevitably lead to difficulties in the study of note-taking, and "cluttered notes and unclear notes" (Wen, 2008) [14]. It is true that notes have individualized elements, and each interpreter's notes are different, but there are also some universal rules and principles existing in a systematic note-taking method, and note-taking textbook should enable students to master these principles. Personalized note-taking are also based on full mastery of those universal principles and rules. According to Andrew Gillies (2009, p. 8) [11], the application of a well-practiced and thought-out note-taking system will mean that the whole practice of consecutive interpreting becomes less of an effort. Therefore although note-taking skill is only a part of the interpreting skills, its role cannot to be underestimated.

\section{Analysis of the Compilation of Existing Note-Taking Textbooks}

\subsection{Textbook Positioning}

The textbook should have a clear positioning, intended readers and writing purpose. The existing four textbooks are different in this respect. See Table 2: 
Table 2. Positioning of the Four Textbooks.

\begin{tabular}{|c|c|c|c|}
\hline Textbook Name & Purpose of Writing & $\begin{array}{l}\text { Textbook } \\
\text { Composition }\end{array}$ & Intended Readers \\
\hline $\begin{array}{l}\text { Practical Guidance } \\
\text { for Note-Taking in } \\
\text { Interpreting }\end{array}$ & $\begin{array}{l}\text { To compile systematically the training method and related } \\
\text { materials of Wuhan University Interpretation Team so as to } \\
\text { help those who are interested in interpreting to master } \\
\text { note-taking skills. }\end{array}$ & $\begin{array}{l}\text { 1. Textbook } \\
\text { 2. CD }\end{array}$ & $\begin{array}{l}\text { English learners who are interested in becoming an } \\
\text { interpreter. }\end{array}$ \\
\hline $\begin{array}{l}\text { English-Chinese } \\
\text { Interpretation } \\
\text { Note-taking Course }\end{array}$ & $\begin{array}{l}\text { Help the learners to train the note-taking method in a } \\
\text { systematic manner, master the correct note-taking method and } \\
\text { effective skills, and develop good note-taking habit. }\end{array}$ & $\begin{array}{l}\text { 1. Textbook } \\
\text { 2. CD }\end{array}$ & $\begin{array}{l}\text { 1. English major or non-English major junior or above } \\
\text { 2. Interpreting lovers with College English Test Band } 6 \\
\text { (CET6), Test for English Majors Band } 4 \text { (TEM4) or } \\
\text { equivalent; } \\
\text { 3. English learners who are preparing for entrance } \\
\text { examination of Master of Translation and Interpreting } \\
\text { (MTI), Master of Art (MA) and Interpreter } \\
\text { Qualification Examinations. }\end{array}$ \\
\hline $\begin{array}{l}\text { Effective } \\
\text { Note-taking }\end{array}$ & $\begin{array}{l}\text { Introduce some theoretical guidance of note-taking skill so as } \\
\text { to solve the basic problems in consecutive interpreting } \\
\text { note-taking, and then let the learners grasp the theory and } \\
\text { improve their ability through note-taking practice. }\end{array}$ & $\begin{array}{l}\text { 1. Textbook } \\
\text { 2. CD }\end{array}$ & $\begin{array}{l}\text { 1. Consecutive interpreting note-taking beginners; } \\
\text { 2. Learners who have a basic foundation. }\end{array}$ \\
\hline $\begin{array}{l}\text { Note-taking for } \\
\text { Consecutive } \\
\text { Interpreting: A } \\
\text { Short Course }\end{array}$ & $\begin{array}{l}\text { This workbook aims to help student interpreters to work } \\
\text { progressively towards a system for note-taking in consecutive } \\
\text { interpreting which is consistent, simple to learn, adaptable and } \\
\text { efficient. }\end{array}$ & Textbook & $\begin{array}{l}\text { 1. Most readers will be involved in, or have been } \\
\text { involved in, some kind of formal interpreter training; } \\
\text { 2. Interpreting lovers. }\end{array}$ \\
\hline
\end{tabular}

The purpose of the four textbooks is relatively clear, but in terms of the intended readers, the English-Chinese Interpretation Note-taking Course is more explicit, and the other three are more vague. They do not specify the English level of intended learners, namely making it clear that weather the textbook is for the lower grades or higher grades, undergraduate or graduate, English major or non-English major. In addition, the first three textbooks are equipped with
CD for students to practice independently.

\subsection{Theory and Techniques of Note-Taking}

The four textbooks cover the theory and skills of the note-taking method to various degrees, but the answers to some key theoretical and technical questions are different. See Table 3 for details:

Table 3. Theory and Skills of Note-taking Method.

\begin{tabular}{|c|c|c|c|c|}
\hline Textbook name & Note-taking symbols & What to note & Note-taking principles & Note-taking skills \\
\hline $\begin{array}{l}\text { Practical Guidance } \\
\text { for Note-Taking in } \\
\text { Interpreting }\end{array}$ & $\begin{array}{l}\text { 1. Mathematics symbols } \\
\text { 2. Common symbols } \\
\text { 3. Graphic symbols } \\
\text { 4. Arrow symbols } \\
\text { 5. English letters } \\
\text { 6. English abbreviations }\end{array}$ & No summary & $\begin{array}{l}\text { 1. Attention-split principle } \\
\text { 2. Borrow principle } \\
\text { 3. Simplification principle } \\
\text { 4. Selection principle }\end{array}$ & $\begin{array}{l}\text { 1. Figure note-taking } \\
\text { 2. Proper nouns note-taking } \\
\text { 3. Logical structure } \\
\text { note-taking }\end{array}$ \\
\hline $\begin{array}{l}\text { English-Chinese } \\
\text { Interpretation } \\
\text { Note-taking Course }\end{array}$ & $\begin{array}{l}\text { 1. Graphic symbol } \\
\text { 2. Punctuation } \\
\text { 3. Mathematical symbols } \\
\text { 4. Arrow symbols } \\
\text { 5. Letters and abbreviations } \\
\text { 6. Affix abbreviations } \\
\text { 7. Greek letters } \\
\text { 8. Chinese character radicals, } \\
\text { abbreviated Chinese characters } \\
\text { or homophonic word } \\
\text { 9. Short name of country name }\end{array}$ & $\begin{array}{l}\text { 1. Information unit } \\
\text { 2. Logical connectives }\end{array}$ & $\begin{array}{l}\text { 1. Vertical arrangement } \\
\text { 2. Use slashes to distinguish } \\
\text { information unit } \\
\text { 3. Turn to the next line with diagonal } \\
\text { layout } \\
\text { 4. Parallel structure needs to be aligned } \\
\text { vertically } \\
\text { 5. Use borrow symbol for repeated } \\
\text { information } \\
\text { 6. Missing mark } \\
\text { 7. Horizontal segmentation, and mark } \\
\text { ending clearly }\end{array}$ & $\begin{array}{l}\text { 1. Use what languages to } \\
\text { take notes? } \\
\text { 2. Are the note-taking } \\
\text { symbols the more the } \\
\text { better? } \\
\text { 3. Why is the beginning and } \\
\text { ending of notes so } \\
\text { important? } \\
\text { 4. What if notes are difficult } \\
\text { to take? } \\
\text { 5. How to practice the } \\
\text { note-taking? }\end{array}$ \\
\hline Effective Note-taking & $\begin{array}{l}\text { Summary of } 118 \text { common } \\
\text { symbols; } 60 \text { common } \\
\text { abbreviations }\end{array}$ & $\begin{array}{l}\text { 1. Information unit } \\
\text { 2. Logical connectives } \\
\text { 3. Isolated elements }\end{array}$ & $\begin{array}{l}\text { 1. The content should be concise } \\
\text { 2. Note-taking should be fast } \\
\text { 3. Form should be flexible }\end{array}$ & $\begin{array}{l}\text { 1. Use different lines } \\
\text { 2. Abbreviations } \\
\text { 3. Diagonal layout } \\
\text { 4. Use slash } \\
\text { 5. Mixing } \\
\text { 6. End }\end{array}$ \\
\hline $\begin{array}{l}\text { Note-taking for } \\
\text { Consecutive } \\
\text { Interpreting: A Short } \\
\text { Course }\end{array}$ & $\begin{array}{l}\text { 1. Mathematics symbol } \\
\text { 2. Science symbol } \\
\text { 3. Music symbol } \\
\text { 4. Keyboard symbol } \\
\text { 5. Punctuation } \\
\text { 6. Maps symbol } \\
\text { 7. Short words in other languages }\end{array}$ & $\begin{array}{l}\text { 1. Idea } \\
\text { 2. Links } \\
\text { 3. Who is speaking } \\
\text { 4. Verb tense and } \\
\text { modal verbs } \\
\text { 5. Proper names, } \\
\text { numbers, dates, and }\end{array}$ & $\begin{array}{l}\text { 1. The notes are divided into four } \\
\text { columns. The first column records } \\
\text { logical words, important information } \\
\text { or blanks, and the second to fourth } \\
\text { column records the subject, verb and } \\
\text { object in a diagonal manner. } \\
\text { 2. Vertical arrangement }\end{array}$ & $\begin{array}{l}\text { 1. How to note clause? } \\
\text { 2. Rules of abbreviations } \\
\text { 3. How to note the verb? } \\
\text { 4. Use of the recall line } \\
\text { 5. Use of the margin } \\
\text { 6. Implicit links } \\
\text { 7. Pro-forms }\end{array}$ \\
\hline
\end{tabular}




\begin{tabular}{|c|c|c|c|c|}
\hline Textbook name & Note-taking symbols & What to note & Note-taking principles & Note-taking skills \\
\hline & $\begin{array}{l}\text { 8. Other alphabets } \\
\text { 9. Registration plate symbol } \\
\text { 10.Currencies symbol } \\
\text { 11. Chemical symbols } \\
\text { 12. Text messaging symbol }\end{array}$ & $\begin{array}{l}\text { lists } \\
\text { 6. Terms to be } \\
\text { transcoded } \\
\text { 7. The last sentence of } \\
\text { a speech }\end{array}$ & $\begin{array}{l}\text { 3. Hierarchies of values (the parallel } \\
\text { structure needs to be aligned } \\
\text { vertically; notes can be moved to the } \\
\text { left or right according to the } \\
\text { hierarchies of value; use brackets to } \\
\text { mark the secondary information) }\end{array}$ & $\begin{array}{l}\text { 8. Noting sooner or later? } \\
\text { 9. Things you didn't catch } \\
\text { 10. How to note the end? }\end{array}$ \\
\hline
\end{tabular}

The fact that the past literature focused mainly on practical aspects of note-taking is quite understandable, considering the nature of the topic. However, these practice-oriented "know-hows" are largely based on the respective author's personal experience and intuition as to what interpreters' notes should be without any theoretically sound ground on which to build their arguments (Someya, 2017, p. 147) [6], which makes theoretical explanation of note-taking all the more important. The four textbooks have summarized several important note-taking theory and skill problems. In terms of theoretical explanation, Note-taking for Consecutive Interpreting: A Short Course has many places worthy of learning and reference for other textbooks. It is a textbook with note-taking skills as the main line. It gives a detailed and comprehensive account of the source of symbols, what to note and how to note, as well as note-taking techniques. Each chapter involves different note-taking techniques and exercise materials for practicing those closely-knited techniques, they are presented in such a thoughtful manner that outlines the whole picture of the note-taking. In comparison, other textbooks are not so systematic about the note-taking principles. The English-Chinese Interpretation Note-taking Course has a comprehensive introduction to issues such like the source of symbols, the principles and techniques of note-taking, for Practical Guidance for Note-Taking in Interpreting, some basic issues are left undiscussed, and Effective Note-taking only takes a simple look at those issues.

\subsection{Practice Material Selection and Design}

Most of the Chinese note-taking textbooks adopt topics as the main line, and the topics, forms and additional contents covered by the textbooks are different. See Table 4 for details:

Table 4. Note-Taking Practice Material Selection and Design.

\begin{tabular}{|c|c|c|c|c|}
\hline Textbook name & $\begin{array}{l}\text { Subject matter for practice } \\
\text { material }\end{array}$ & Form & Additional content & Is it suitable for independent study \\
\hline $\begin{array}{l}\text { Practical Guidance } \\
\text { for Note-Taking in } \\
\text { Interpreting }\end{array}$ & $\begin{array}{l}\text { 1. Economy and trade } \\
\text { 2. Diplomacy and politics } \\
\text { 3. Energy and Environment } \\
\text { 4. Sports and tourism } \\
\text { 5. Culture and education } \\
\text { 6. Other hot topics }\end{array}$ & $\begin{array}{l}\text { 1. } 240 \text { sentences of } \\
\text { Chinese-English and } \\
\text { English-Chinese } \\
\text { note-taking practice } \\
\text { 2. } 196 \text { paragraphs } \\
\text { 3. Two long speeches }\end{array}$ & $\begin{array}{l}\text { 1. Translation of idioms, } \\
\text { proverbs, poems } \\
\text { 2. Interpreting vocabularies } \\
\text { for different topics }\end{array}$ & $\begin{array}{l}\text { Practice materials start with sentence to } \\
\text { paragraph and long speech with } \\
\text { increasing level of difficulty, which is in } \\
\text { line with the law of learning. There are } \\
\text { symbol explanations below each note } \\
\text { demonstration, which are very } \\
\text { beginners-friendly. }\end{array}$ \\
\hline $\begin{array}{l}\text { English-Chinese } \\
\text { Interpretation } \\
\text { Note-taking } \\
\text { Course }\end{array}$ & $\begin{array}{l}\text { 1. Global affairs } \\
\text { 2. Diplomatic cooperation } \\
\text { 3. National conditions and national } \\
\text { policy } \\
\text { 4. Economy and trade } \\
\text { 5. Tourism } \\
\text { 6. International conference } \\
\text { 7. Global issues } \\
\text { 8. Business and commerce } \\
\text { 9. Society and culture } \\
\text { 10. Educational development, etc. }\end{array}$ & $\begin{array}{l}\text { 1. } 209 \text { paragraph practice } \\
\text { 2. } 30 \text { testing paragraphs }\end{array}$ & $\begin{array}{l}\text { 1. Organization vocabulary } \\
\text { 2. Title vocabulary } \\
\text { 3. Foreign trade vocabulary } \\
\text { 4. Common terms used in } \\
\text { the Olympic Games } \\
\text { 5. Environment vocabulary } \\
\text { 6. News and media } \\
\text { vocabulary } \\
\text { 7. Major languages used } \\
\text { around the world } \\
\text { 8. Common Chinese idioms }\end{array}$ & $\begin{array}{l}\text { This textbook is rich in topics, and it } \\
\text { proposes a training method of taking } \\
\text { notes while reading the source language } \\
\text { first, and then taking notes for the same } \\
\text { passage by listening to the source } \\
\text { language again, reading notes in source } \\
\text { language first and then in target language, } \\
\text { which is very suitable for students to } \\
\text { practice independently. However, there is } \\
\text { no explanation for the symbols below the } \\
\text { notes demonstration. Some places require } \\
\text { teacher's guidance. }\end{array}$ \\
\hline $\begin{array}{l}\text { Effective } \\
\text { Note-taking }\end{array}$ & $\begin{array}{l}20 \text { topics covering ceremonial } \\
\text { speeches, conference speeches, } \\
\text { academic forums, economic } \\
\text { cooperation, finance and trade, } \\
\text { reform and opening up, international } \\
\text { relations, technological innovation, } \\
\text { environmental protection, culture, } \\
\text { etc. }\end{array}$ & $\begin{array}{l}\text { Part one: the principle of } \\
\text { note-taking } \\
\text { Part two: Note-taking } \\
\text { practice covering } 20 \text { topics, } \\
\text { each topic includes English to } \\
\text { Chinese, Chinese to English } \\
\text { practice and related } \\
\text { vocabulary. }\end{array}$ & Various topic related words & $\begin{array}{l}\text { The textbook has multiple topics for } \\
\text { practice, and most practice materials are } \\
\text { simple, mostly sentences and short } \\
\text { paragraphs, and there are explanations } \\
\text { for notes and translation difficulties } \\
\text { under each paragraph. Therefore, it is } \\
\text { quite suitable for self-study of beginners. }\end{array}$ \\
\hline $\begin{array}{l}\text { Note-taking for } \\
\text { Consecutive } \\
\text { Interpreting: A } \\
\text { Short Course }\end{array}$ & 25 note-taking paragraphs & $\begin{array}{l}\text { Part one: the basics } \\
\text { step-by-step } \\
\text { Part two: fine-tuning (further } \\
\text { expound on note-taking skills) } \\
\text { Part three: Notes and analysis } \\
\text { of the speech }\end{array}$ & None & $\begin{array}{l}\text { This textbook has very detailed } \\
\text { introduction for all the steps and skills of } \\
\text { the note-taking method, supplemented by } \\
\text { easy-to-difficult training materials. So it } \\
\text { is very suitable for self-study. }\end{array}$ \\
\hline
\end{tabular}


Note-taking practice is the main part of the note-making textbook, and its selection and design are very important. The Practical Guidance for Note-Taking in Interpreting is rich in practice topics which combines both relatively easy and moderately difficult training materials ranging from sentences, paragraphs to speeches, coupled with some further explanations for symbols after extemporaneous hand-written note-taking demonstration, making it all the more suitable for undergraduate interpreting and translation majors to study on their own. As one of the MTI series of textbooks for college students in translation and interpreting, English-Chinese Interpretation Note-taking Course is more difficult, it does not contain any sentence practice, and all of the training materials are paragraphs. The reference note-taking demonstration is also handwritten version, which better reflects the spontaneity of on-site interpreting. In addition, the first and the second chapter of the textbook are theoretical parts, the content is informative, which introduces the self-training method of note-taking, it proposes a training method of taking notes while reading the source language first, and then taking notes for the same passage by listening to the source language again, reading notes in source language first and then in target language, which is in line with the law of learning and teaching of note-taking skills, therefore this textbook is suitable for more advanced students who want to further consolidate and practice note-taking. As far as Effective Note-taking is concerned, the practice materials for most topics are relatively simple. Each paragraph is accompanied by detailed symbol explanations and each topic is followed by relevant vocabulary, thus it is suitable for beginners to learn by themselves. The disadvantage is that all the note-taking demonstrations are not handwritten version, but designed computer written version. Note-taking for Consecutive Interpreting: A Short Course is a note-taking skill-oriented practical handbook written in English. Professor Zhang Ailing said in the reading guide of this book, "The most important idea of the book is that the author believes note-taking is the most comprehensive and accurate analysis of the source language, and structure is the soul of note-taking, and the design of the book is based on this concept, which is also the most helpful place for readers or interpreters compared to other note-taking textbooks." (Gillies, 2009, p. 2) [11]. This handbook introduces the note-taking system in a step-by-step manner; each chapter involves a specific note-taking technique or principle in note-taking practice, coupled with paragraph exercise. The disadvantage is that there is little practice material, and the topic mainly focuses on economy and politics, the same paragraph occurred multiple times for different training purpose, and there is no $\mathrm{CD}$, which makes self-learning for students a bit difficult.

\section{Conclusion}

Due to serious shortage of interpreting note-taking textbooks and all sorts of problems existing in those textbooks, the current need for interpreting teaching has not been met, and there is an urgent need calling for the new high-quality note-taking textbooks. Through the analysis of the abovementioned four textbooks, it is found that for some textbooks, the intended readers are unclear, the theoretical part is missing, the skill training process is incomplete, the reference note-taking is far from the real consecutive interpreting note-taking, or the textbook is not so user-friendly for independent practice. Those are problems future note-taking textbooks should try to avoid. At present, the domestic textbooks are generally based on topics and lack of systematicity in the theoretical and technical aspects of the note-taking, only focusing on a large number of practice. It fails to sort out and summarize the principles and techniques of the note-taking skill and lacks theoretical support. In response to these problems, future note-taking textbooks can be improved from the following aspects:

\subsection{Clarifying Positioning of the Note-Taking Textbook}

Note-taking skills help to lay a solid foundation for consecutive interpreting. Generally speaking, universities offer consecutive interpreting courses for English or translation and interpreting major at senior level. Therefore, the ideal note-taking textbook should be oriented towards second or third year English or translation/interpreting major, or English lovers who have a certain foundation (such as the English CET-4 and CET-6 holders), so it is necessary to choose practice materials suitable for those intended users.

\subsection{The Selected Topics Should Be Closely Integrated with Note-Taking Techniques}

Most of the existing textbooks in China use different topics as the main line to design the outline of note-taking textbook, ignoring the importance of note-taking skills. The ideal note-taking textbook should explain important issues for note-taking at the beginning, such as frequently used symbols in note-taking, why to note, what to note and how to note. The following chapters should be compiled in combination with different interpretation topics and specific note-taking techniques. The selection of training materials should reflect the note-taking skills in the specific chapter, for example, different chapter should be devoted to discuss how to note down tense, logical connectives, parallel structure, numbers, proper nouns, quotations, clauses, long sentences, and so on. Such topics as politics, diplomacy, economics, commerce, culture, tourism, education, environmental protection, technology etc., can be included in the textbook to ensure that students are exposed to the most frequently occurred topics in interpreting exams or professional career. And each chapter should provide a wealth of exercise materials to help students in their effort to develop a thorough command of their languages in a very broad range of registers and topics.

\subsection{Diversified Training Materials and Training Methods}

Note-taking training materials should not be too long at the beginning, usually learners will start with easy sentences before they move on to practice note-taking for moderately difficult paragraphs and short speeches. The note-taking 
practice for sentences should highlight the integration of note-taking techniques, while paragraph note-taking can be combined with other training methods, such as taking notes by reading or listening to the paragraph, reading notes in source language and target language separately, sight interpreting and back interpreting. Taking a paragraph of about half a minute length as an example, the training can be completed in four steps: 1) playing the recording for one or two times first, the student taking notes according to what he hears; 2) modifying the notes while reading the original text, checking whether the principles of note-taking have been applied correctly and symbol combinations are used properly, etc.; 3) reading the notes in source language and produce the interpretation in target language, 4) Performing a back interpreting to the source language according to the reference translation.

\subsection{Establishing a Three-Dimensional Textbook System}

At present, many interpreting textbooks on the market offer audio materials for students to train independently, and note-taking textbook should be no exception. In addition, some interpreting textbooks even offer bibliography that includes a section of Internet links to audio or video speeches for listening and interpretation practice, and the practice materials from those websites are updated from time to time to make sure students have access to the latest training materials. This is also worthy of reference for the future note-taking textbook. Therefore, the ideal note-taking textbook should offer audio or video practice material (live recordings of conferences would be the best), and reference interpreting (interpretation version instead of translation version). In addition, website or other platforms that go together with the textbook would be highly recommended so that students can practice more independently, thus forming a multi-dimensional, multi-functional textbook system.

\section{References}

[1] Gile, D. Basic Concepts and Models for Interpreter and Translator Training [M]. Amsterdam \& Philadelphia: John Benjamins Publishing, 1995.

[2] Nolan, J. Interpreting: Techniques and Exercises [M]. Tonawanda: Multilingual Matters, 2005.
[3] Jones, Roderick. Conference Interpreting Explained [M]. Shanghai: Shanghai Foreign Language Education Press, 2008.

[4] Seleskovitch, D. (1968). L'interprète dans les conférences internationales, Problèmes de langage et de communication. Paris: Minard. English translation (1978). Interpreting for International Conferences. Translated by S. Dailey and E. N. McMillan. Washington, DC: Pen \& Booth.

[5] Mikasa, Michaela. Notation Language and Notation Text: A Cognitive-linguistic Model of Consecutive Interpreting [A]. In Yasumasa Someya (Eds.) Consecutive Notetaking and Interpreter Training. New York: Routledge. 2017.

[6] Someya, Yasumasa, A Propositional Representation Theory of Consecutive Notes and Notetaking [A]. In Yasumasa Someya (Eds.) Consecutive Notetaking and Interpreter Training. New York: Routledge. 2017.

[7] Ito, Hiromi, Theory and Practice of Notetaking Cognitive-psychological Perspective [A]. In Yasumasa Someya (Eds.) Consecutive Notetaking and Interpreter Training. New York: Routledge. 2017.

[8] Wu, Zhongming. Practical Guidance for Note-Taking in Interpreting [M]. Wuhan: Wuhan University Press, 2007.

[9] Zhu, Qianlian. Effective Note-taking [M]. Beijing: People's Education Press, 2009.

[10] Wang, Tao. English-Chinese Interpretation Note-taking Course, Wuhan: Wuhan University Press, 2012.

[11] Gillies, Andrew. Note-Taking for Consecutive Interpreting: A Short Course [M]. Shanghai: Shanghai Foreign Language Education Press, 2009.

[12] Wang, Jinbo \& Wang, Yan. Characteristics of Interpreting and Interpreting textbooks: Problems and Prospects [J]. Foreign Language World, 2006 (5): 41-47.

[13] Yang, Cheng-shu, Semiology and Conceptual Schema in Consecutive Notes [A]. In Yasumasa Someya (Eds.) Consecutive Notetaking and Interpreter Training. New York: Routledge. 2017.

[14] Wen, Nianfang. Cognitive Analysis and Reflection on Interpreting Note-taking [J]. Shanghai Translation, 2008 (4): 43-46.

[15] Rozan, Jean-Francois. La Prise de Notes en Interprétation Consécutive $[\mathrm{M}]$. Geneva: Georg, translated by Andrew Gillies as Note-taking in Consecutive Interpreting, Cracow: Tertium, 2003. 